研 究

\title{
ダブルペロブスカイト $\mathrm{Pb}_{2} \mathrm{FeReO}_{6}$ の合成と物性
}

\author{
西村 浩輔, 東 正樹, 高野 幹夫, 島川 祐一 \\ 京都大学化学研究所， $=611-0011$ 京都府宇治市五ヶ庄.
}

\section{Synthesis and Physical Properties of Double Perovskite $\mathrm{Pb}_{2} \mathrm{FeReO}_{6}$}

\author{
Kousuke Nishimura, Masaki Azuma, Mikio Takano and Yuichi Shimakawa \\ Institute for Chemical Research, Kyoto University, Gokasho, Uji 611-0011, Japan.
}

Received October 24, 2007

\begin{abstract}
SYNOPSIS
A double perovskite $\mathrm{Pb}_{2} \mathrm{FeReO}_{6}$ was prepared at a high pressure $(6 \mathrm{GPa})$ and high temperature $\left(1000^{\circ} \mathrm{C}\right)$ condition. The crystal structure determined by the synchrotron X-ray powder diffraction study was centrosymmetric with the space group $I 4 / \mathrm{m}$ despite the presence of $\mathrm{Pb}^{2+}$ ion in the A site. No structural transition to the lower symmetry was observe down to $23 \mathrm{~K}$. This compound exhibited a ferrimagnetic transition at $420 \mathrm{~K}$. The saturation magnetization varied with the degree of $\mathrm{Fe}^{3+} / \mathrm{Re}^{5+}$ ordering.
\end{abstract}

KEY WORDS

$\mathrm{Pb}_{2} \mathrm{FeReO}_{6}$, double perovskite, high pressure synthesis, ferrimagnetic transition

\section{1 緒 言}

強磁性と強誘電性のように, 複数の秩序状態を同時に発現 する物質はマルチフェロイクスと呼ばれる.磁性と強誘電性 の間の結合が十分に強ければ相関的に物性を制御できる可能 性を秘めており, 盛んに研究されている. 例えば, $\mathrm{Bi}_{2} \mathrm{NiMnO}_{6}$ は強磁性・強誘電体である ${ }^{1)}$. 強磁性は, $\mathrm{e}_{\mathrm{g}}$ 電子を持つ $\mathrm{Ni}^{2+}$ と $\mathrm{t}_{2 \mathrm{~g}}$ 電子のみを持つ $\mathrm{Mn}^{4+}$ が岩塩型に秩序配列することにより, 金森-Goodenough則に従って実現している. 強誘電性は, $\mathrm{Bi}^{3+}$ が持つ $6 \mathrm{~s}^{2}$ 孤立電子対と共有結合性の強い $\mathrm{Bi}-\mathrm{O}$ 結合の働きに よって, 反転対称のない空間群に歪んで分極を生じることに 起因すると考えられる。しかし， $\mathrm{Bi}_{2} \mathrm{NiMnO}_{6}$ の磁気転移温度 は $140 \mathrm{~K}$ と室温よりもかなり低く, 実用化のためにはその向 上が望まれる。

一方, 室温より高い磁気転移温度を示すぺロブスカイト酸 化物として, $\mathrm{Sr}_{2} \mathrm{MReO}_{6}(\mathrm{M}=\mathrm{Cr}, \mathrm{Fe})$ が知られている ${ }^{2,3)}$.これ らは, $\mathrm{Bi}_{2} \mathrm{NiMnO}_{6}$ と同様に, ペロブスカイト $\left(\mathrm{ABO}_{3}\right)$ 構造の, AサイトにSr, BサイトにM と Reが岩塩型に規則配列したダ ブルペロブスカイト構造である(Fig.1). いずれもMイオンと Reイオンのスピンが反対向きに揃うフェリ磁性体であり, $\mathrm{M}=$ $\mathrm{Cr}, \mathrm{Fe}$ のそれぞれについて，転移温度は $635 \mathrm{~K}, 400 \mathrm{~K} て ゙, 5 \mathrm{~K}$, $5 \mathrm{~T}$ における磁化は $0.3 \mu_{\mathrm{B}}, 2.6 \mu_{\mathrm{B}}$ と報告されている. そこで,
磁化の大きい $\mathrm{Sr}_{2} \mathrm{FeReO}_{6}$ について, $\mathrm{Sr}^{2+}$ を $\mathrm{Bi}^{3+}$ と同様に $6 \mathrm{~s}^{2}$ 孤 立電子対を持つ $\mathrm{Pb}^{2+}$ に置き換えることにより, 強誘電性を実 現できないかと考えた。 $\mathrm{Pb}_{2} \mathrm{MReO}_{6}$ のダブルペロブスカイト 構造を持つ物質は, $\mathrm{M}=\mathrm{Mn}$ のみが報告されているが, 反転対

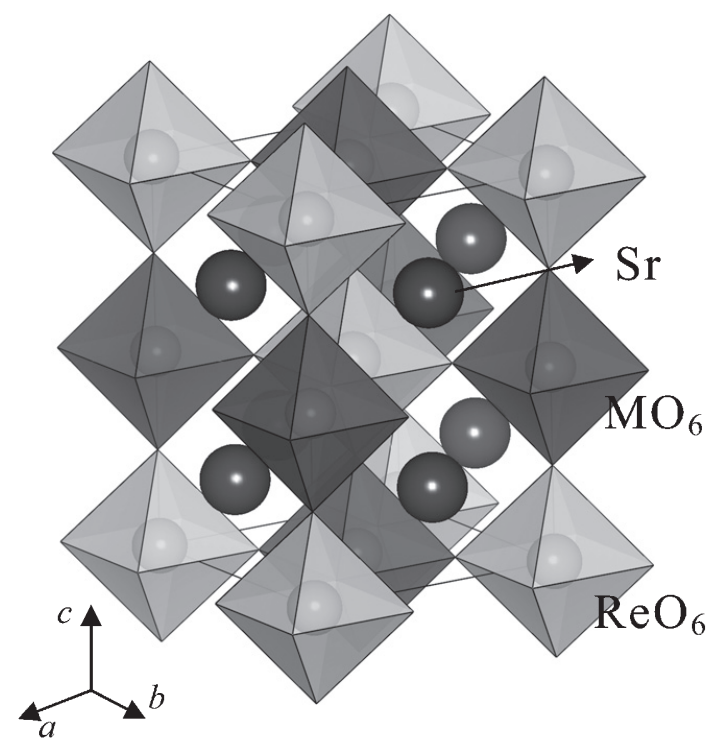

Fig.1 Crystal structure of $\mathrm{Sr}_{2} \mathrm{MReO}_{6}$. 
称性のある $P 21 / n$ 空間群を持ち, 磁気転移温度は約 $100 \mathrm{~K}$, 室 温で約 $100 \Omega \mathrm{cm}$ の半導体である ${ }^{4)}$.

$\mathrm{Pb}_{2} \mathrm{FeReO}_{6}$ の組成式を持った物質は, 酸素欠損したパイロ クロアとして報告されており，125K 付近で磁気転移を起こ す5).この物質は, $\mathrm{Ar}$ ガス気流中で $550^{\circ} \mathrm{C}, 12$ 時間の条件で 合成される，今回，高圧下での合成により，パイロクロアよ りも密度が高く, 先述した $\mathrm{Sr}_{2} \mathrm{FeReO}_{6}$ と同じダブルペロブス カイト構造の $\mathrm{Pb}_{2} \mathrm{FeReO}_{6}$ の合成に成功した. 合成条件により 飽和磁化に差が見られたことから, 異なる条件で合成した試 料の構造, 物性の関係について調べた。

\section{2 合成および測定}

$\mathrm{PbO}$ (99.9\%), $\mathrm{ReO}_{3}$ (99.9\%), $\mathrm{Fe}_{2} \mathrm{O}_{3}$ (99.999\%), $\mathrm{Fe}$ (99.99\%) を 化学量論比で混合し金カプセルに封入したものを，キュー ビックアンビル型の高圧合成装置を用いて $6 \mathrm{GPa}$ の圧力をか け, $1000^{\circ} \mathrm{C} て ゙ ~ 30$ 分間熱処理した. 加熱後, 室温まで急冷し た試料, 及び, 室温まで 8 時間かけて徐冷した試料の, 2 種類 の試料を用意した。両方の試料について, SPring-8のシンク ロトロン放射光 $(\lambda=0.42 \AA)$ を用いて BL02B2 の大型デバイ シェラーカメラによって粉末 X線回折を測定した. 得られた 回折データを, RIETAN-20006) を用いてリートベルト法によ り解析した. また, RINT2500 $(\mathrm{Cu}-\mathrm{K} \alpha)$ を使用し, $23 \sim 293 \mathrm{~K}$ での低温粉末 X線回折を測定した. 磁性は, SQUID (MPMS2, Quantum Design 社) を使用し，300〜 560K, $100 \mathrm{Oe}$ での磁化 率の温度依存性と $5 \mathrm{~K},-5 \sim 5 \mathrm{~T}$ での磁化の磁場依存性を測定 した。また, 電気抵抗は, PPMS (Quantum Design 社) を使用 し, 5〜300 Kでの電気抵抗率を測定した.

\section{3 結果と考察}

3.1 放射光粉末 X 線回折

室温での回折パターンのリートベルト解析結果をFig.2に, 構造パラメーターを Table 1 に示す. 徐冷.急冷試料ともに,
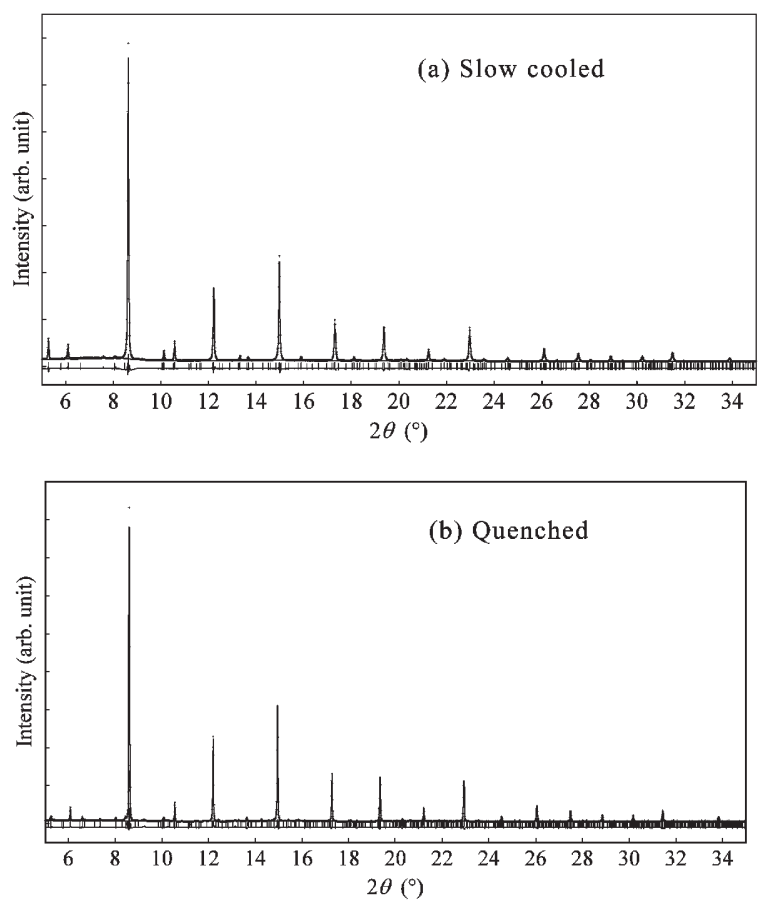

Fig.2 Synchrotron X-ray powder diffraction patterns and the results of Rietveld refinements for slow cooled (a) and quenched (b) $\mathrm{Pb}_{2} \mathrm{FeReO}_{6}$ taken at the room temperature. The calculated (solid line) and observed (dot) data are shown at the top with the position of Bragg reflection (the vertical marks) in the middle and the difference trace at the bottom.

Table 1 Refined structural parameters of slow cooled (a) and quenched (b) $\mathrm{Pb}_{2} \mathrm{FeReO}_{6}$.

(a) Slow cooled sample

\begin{tabular}{|l|l|l|l|l|l|}
\hline Atom & $\mathrm{g}$ & $\mathrm{x}$ & $y$ & $z$ & $\mathrm{~B}$ \\
\hline $\mathrm{Pb}$ & 0.5 & 0.0 & 0.5 & $0.2244(1)$ & 0.8 \\
\hline $\mathrm{Fe} 1$ & $0.103(1)$ & 0.0 & 0.0 & 0.0 & 0.5 \\
\hline $\mathrm{Re} 1$ & 0.897 & 0.0 & 0.0 & 0.0 & 0.5 \\
\hline $\mathrm{Re} 2$ & 0.103 & 0.0 & 0.0 & 0.5 & 0.5 \\
\hline $\mathrm{Fe} 2$ & 0.897 & 0.0 & 0.0 & 0.5 & 0.5 \\
\hline $\mathrm{O} 1$ & 1.0 & $0.246(15)$ & $0.252(11)$ & 0.0 & 1.0 \\
\hline $\mathrm{O} 2$ & 1.0 & 0.0 & 0.0 & $0.247(17)$ & 1.0 \\
\hline
\end{tabular}

$a=5.61595(11) \AA, c=7.94556(35) \AA$, Space group: $I 4 / m, \mathrm{Rwp}=3.23 \%$

(b) Quenched sample

\begin{tabular}{|l|l|l|l|l|l|}
\hline Atom & $\mathrm{g}$ & $x$ & $y$ & $z$ & $\mathrm{~B}$ \\
\hline $\mathrm{Pb}$ & 0.5 & 0.0 & 0.5 & $0.2232(1)$ & 0.8 \\
\hline $\mathrm{Fe} 1$ & $0.296(2)$ & 0.0 & 0.0 & 0.0 & 0.5 \\
\hline $\mathrm{Re} 1$ & 0.704 & 0.0 & 0.0 & 0.0 & 0.5 \\
\hline $\mathrm{Re} 2$ & 0.296 & 0.0 & 0.0 & 0.5 & 0.5 \\
\hline $\mathrm{Fe} 2$ & 0.704 & 0.0 & 0.0 & 0.5 & 0.5 \\
\hline $\mathrm{O} 1$ & 1.0 & $0.252(19)$ & $0.258(15)$ & 0.0 & 1.0 \\
\hline $\mathrm{O} 2$ & 1.0 & 0.0 & 0.0 & $0.235(5)$ & 1.0 \\
\hline
\end{tabular}

$a=5.61803(7) \AA, c=7.94581(21) \AA$, Space group: $I 4 / m, \mathrm{Rwp}=6.25 \%$ 
ほぼ $\mathrm{Pb}_{2} \mathrm{FeReO}_{6}$ の単相試料が得られていることがわかった 不純物としては, 徐冷試料には $\mathrm{ReO}_{2}(0.08 \%), \mathrm{ReO}_{3}(0.40 \%)$, 急冷試料には $\mathrm{ReO}_{2}(2.9 \%), \mathrm{ReO}_{3}(0.57 \%), \mathrm{Pb}\left(\mathrm{ReO}_{4}\right)_{2}(0.60 \%)$ が 含まれていた. 結晶構造は, $\mathrm{Sr}_{2} \mathrm{FeReO}_{6}$ と同じく反転対称性の ある空間群 $I 4 / m$ のダブルペロブスカイト構造で, 徐冷試料の 格子定数は $a=5.6159$ (1) $\AA, c=7.9455$ (3) $\AA$, 急冷試料は $a=$ $5.6180(1) \AA ̊, c=7.9458$ (2) $\AA$ である. $\mathrm{Pb}$ の原子座標を $z$ 軸方向 に分割したモデルを仮定することでフィッティングの精度を 大幅に向上することができたが, $\mathrm{Pb}$ 原子自体が特定の方向に 偏っているわけではない.

ダブルペロブスカイト構造においては, BサイトはFeのサ イトと Reのサイトに分かれている，この物質では， Feサイ トにReが，ReサイトにFeが混入していることが疑われたの で，それぞれのサイトの $\mathrm{Fe} / \mathrm{Re}$ の占有率を精密化した。 この 際, 熱振動パラーメーター B は占有率 $\mathrm{g}$ との相関が大きいた め, B を固定して解析した. その結果, 徐冷試料と急冷試料 について, $\mathrm{Fe} / \mathrm{Re} の$ 占有率に明確な差が見られた. $\mathrm{Fe}$ サイト $(\mathrm{Fe} 2 / \mathrm{Re} 2)$ について, 徐冷試料では $\mathrm{Fe}: \mathrm{Re}=0.897: 0.103$, 急 冷試料では $\mathrm{Fe}: \mathrm{Re}=0.704: 0.296$ の割合であった (Table 1). こ のことは, 合成時の冷却速度によりBサイトイオンの秩序度 が大きく異なることを示している.

Bond Valence Sum ${ }^{7}$ により $\mathrm{Fe}$ とRの価数を計算したところ， 徐冷試料について Fe; $3.24, \mathrm{Re} ; 4.27$ を得た. この計算では $\mathrm{Fe} /$ Re の完全な秩序配列を仮定して計算している事を考慮する と, $\mathrm{Fe}$ は Reの価数に, Reは $\mathrm{Fe}$ の価数に近づいていると考元 られ, Feは 3 価, Reは 5 価というモデルが妥当と思われる. 3.2 低温粉末 $\mathrm{X}$ 線回折

構造解析から, 反転対称性のある空間群 $I 4 / m$ を持ち, 少な くとも室温では強誘電相でないことがわかった，そこで, 強 誘電転移温度が室温以下にある可能性を考光, 低温粉末 X 線 回折を測定した. その結果を Fig. 3 に示す. $23 \mathrm{~K}$ まで冷却し ても構造の変化は見られなかった. また, Fig.4に示すように

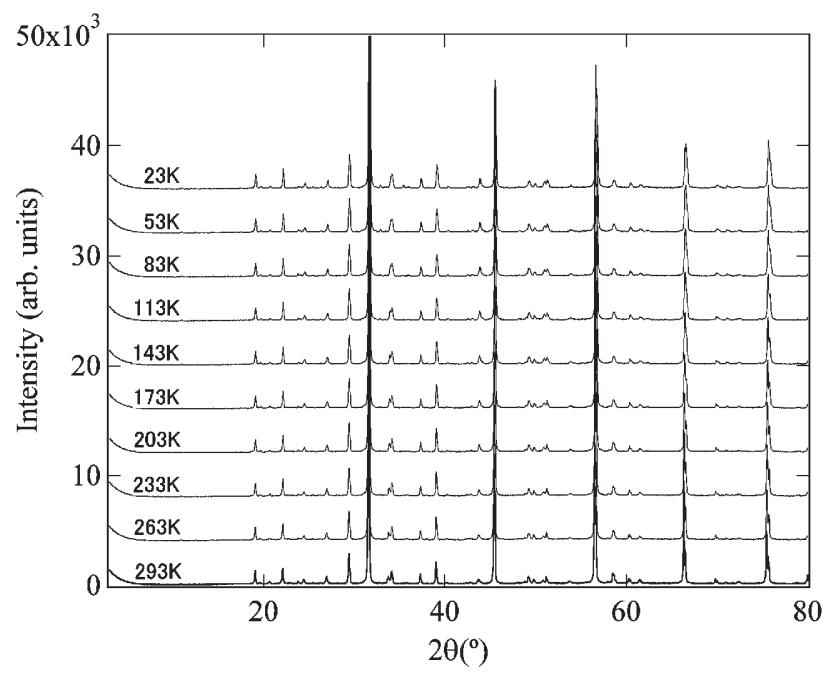

Fig.3 Powder XRD patterns for slow cooled $\mathrm{Pb}_{2} \mathrm{FeReO}_{6}$ measured at various temperatures between 23 and $293 \mathrm{~K}$.
格子定数の変化も単調で, 構造相転移を示唆するような異常 は観測されなかった。

3.3 磁化測定

磁化の磁場依存性を Fig.5に示す. $5 \mathrm{~K}$ での飽和磁化は, 徐 冷試料が約 $2.4 \mu_{\mathrm{B}}$, 急冷試料が約 $1.2 \mu_{\mathrm{B}}$ である. ここで, 3.1 に おいて考察した $\mathrm{Fe}$ と Reの価数を元にして, 期待される飽和 磁化を計算した. Feが 3 価で $S=5 / 2$, Reが 5 価で $S=1$ であ るから，それぞれ $5 \mu_{\mathrm{B}}, 2 \mu_{\mathrm{B}}$ の磁化を持つ. Table 1 の Fe1/Re1, $\mathrm{Fe} 2 / \mathrm{Re} 2$ 両サイトの占有率を考慮すると, 徐冷試料について,

$\mathrm{Fe} 1 / \operatorname{Re} 1$ サイト $\cdots 5 \times 0.103+2 \times 0.897=2.309$

$\mathrm{Re} 2 / \mathrm{Fe} 2$ サイト $\cdots .5 \times 0.897+2 \times 0.103=4.691$

の磁化が期待され，それぞれのサイトのスピンが反強磁性的 に規則配列していると考えると, 飽和磁化は 4.691-2.309= $2.382\left(\mu_{\mathrm{B}}\right)$ と算出される. 同様の計算を急冷試料について行な

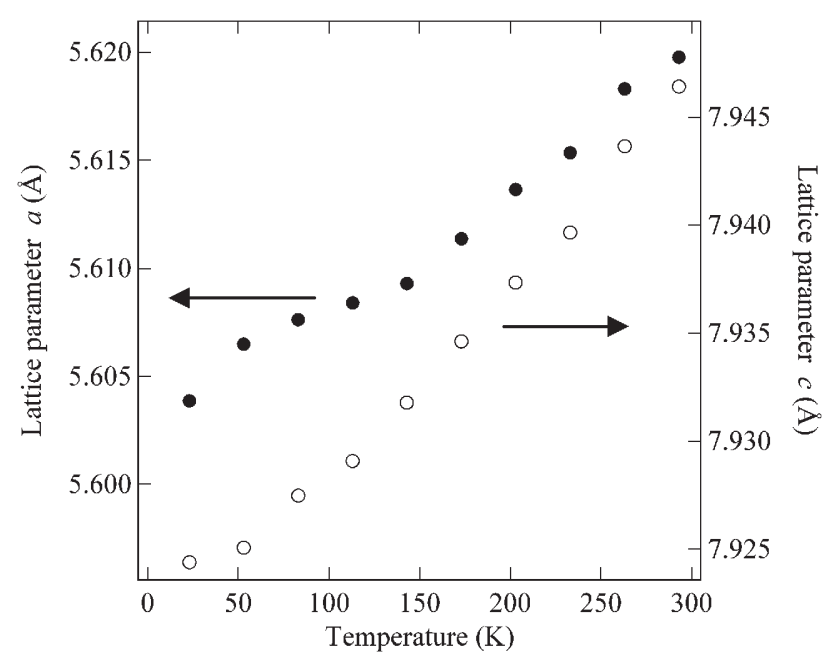

Fig.4 Temperature dependence of lattice parameters for slow cooled $\mathrm{Pb}_{2} \mathrm{FeReO}_{6}$.

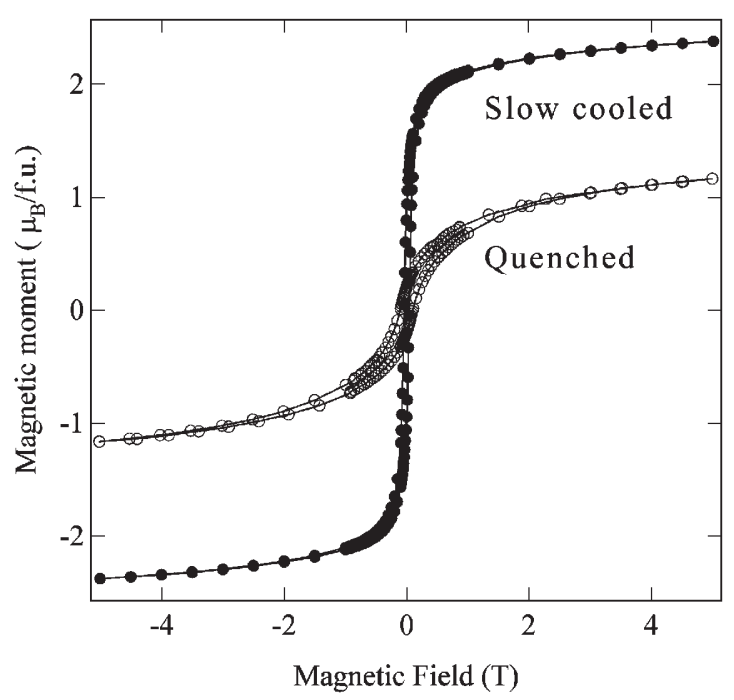

Fig.5 Magnetization curves of $\mathrm{Pb}_{2} \mathrm{FeReO}_{6}$ measured at $5 \mathrm{~K}$. 


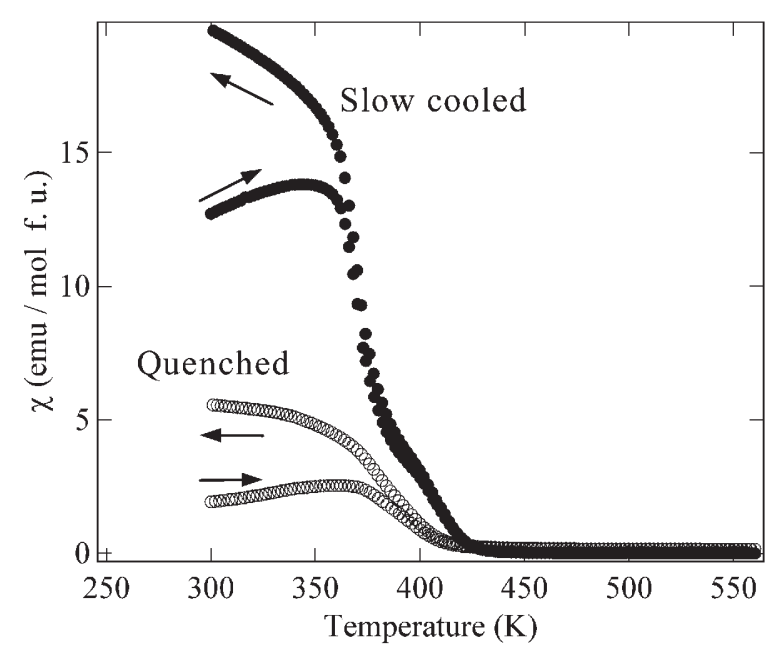

Fig.6 Temperature dependence of magnetic susceptibility of $\mathrm{Pb}_{2} \mathrm{FeReO}_{6}$ in an external field of $100 \mathrm{Oe}$.

うと, $1.224\left(\mu_{\mathrm{B}}\right)$ が得られる.これらの計算結果は, 実験結果 (Fig.5) と非常によく一致するため, $\mathrm{Pb}_{2} \mathrm{FeReO}_{6}$ が $\mathrm{Fe}^{3+}$ と $\mathrm{Re}^{5+}$ の酸化状態を持つフェリ磁性体であることを裹付けている. $300 \sim 560 \mathrm{~K}$ での磁化率の温度依存性をFig.6に示す. 徐冷・ 急冷試料ともに， $420 \mathrm{~K}$ 付近に磁気転移が見られた．このこ とから, 期待通り, 室温以上の転移温度を持つフェリ磁性体 が得られたことがわかった.

\section{4 電気抵抗測定}

徐冷試料の電気抵抗の測定結果を Fig.7 に示す. 室温で約 $0.07 \Omega \mathrm{cm}$ で, 半導体的振る舞いをする. 急冷試料についても 同様であった.このことも, 絶縁体の強誘電体を期待した当 初の目的とは異なった結果である。 また，これは $\mathrm{Sr}_{2} \mathrm{FeReO}_{6}$ に見られる振る舞いとよく一致している ${ }^{8} . \mathrm{Sr}_{2} \mathrm{FeReO}_{6}$ は, バ ンド計算から $\mathrm{Fe}^{3+}$ と $\mathrm{Re}^{5+}$ が秩序配列することでハーフメタル となることが示されているが, $\mathrm{Pb}_{2} \mathrm{FeReO}_{6}$ についても結晶構 造が同じことから同様の機構が考えられる.

\section{4 結 論}

高压下での合成により，ダブルペロブスカイト構造の $\mathrm{Pb}_{2} \mathrm{FeReO}_{6}$ の合成に初めて成功した. 空間群は反転対称性の ある $I 4 / m$ で, 期待した強誘電相ではなかった. また, $23 〜 293 \mathrm{~K}$ においても反転対称性を破るような構造の変化は見られな かった。

徐冷と急冷という2つの異なる合成条件の試料を作ったとこ ろ, 磁化曲線から見積もられる飽和磁化に差が見られた.リ一 トベルト解析により，その差は $\mathrm{Fe}^{3+}$ と $\mathrm{Re}^{5+}$ の秩序配列の度合 いの違いによるものとわかった. いずれも約 $420 \mathrm{~K}$ でフェリ 磁性体へと磁気転移し, 電気抵抗は半導体的振る舞いをした.

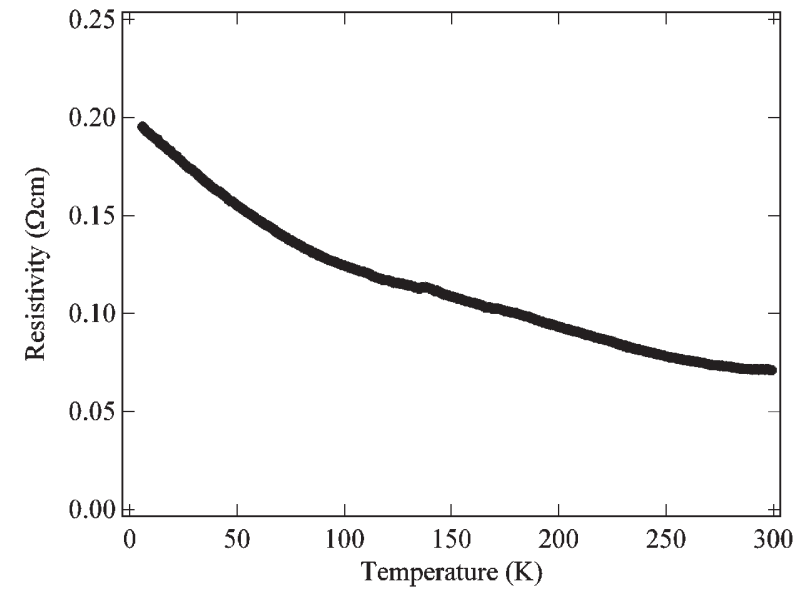

Fig.7 Temperature dependence of electric resistivity of slow cooled $\mathrm{Pb}_{2} \mathrm{FeReO}_{6}$.

\section{文献}

1) M.Azuma, K.Takata, T.Saito, S.Ishiwata, Y.Shimakawa, and M.Takano: "A Designed New Ferromagnetic Ferroelectric $\mathrm{Bi}_{2} \mathrm{NiMnO}_{6}$ ", J. Amer. Chem. Soc., 127(2005) 8889-8892.

2) M.Abe, T.Nakagawa, and S.Nomura: "Magnetic and Mössbauer Studies of the Ordered Perovskites $\mathrm{Sr}_{2} \mathrm{Fe}_{1+\mathrm{x}} \mathrm{Re}_{1-\mathrm{x}} \mathrm{O}_{6}$ ", J. Phys. Soc. Jpn., 35(1973) 1360-1365.

3) H.Kato, T.Okuda, Y.Okimoto, Y.Tomioka, Y.Takenoya, A.Ohkubo, M.Kawasaki, and Y.Tokura: "Metallic ordered double-perovskite $\mathrm{Sr}_{2} \mathrm{CrReO}_{6}$ with maximal Curie temperature of 635 K", Appl. Phys. Lett., 81(2002)328-330.

4) K.Ramesha, L.Sebastian, B.Eichhorn, and J.Gopalakrishnan: "Perovskite and Pyrochlore Modifications of $\mathrm{Pb}_{2} \mathrm{MnReO}_{6}$ : Synthesis, Structure, and Electronic Properties", Chem. Mater., 15(2003)668-674.

5) K.Ramesha, L.Sebastian, B.Eichhorn, and J.Gopalakrishnan: $" \mathrm{~Pb}_{2} \mathrm{FeReO}_{6}$ : new defect pyrochlore oxide with a geometrically frustrated Fe/Re sublattice", J. Mater. Chem., 13(2003)20112014.

6) F.Izumi and T.Ikeda: "A Rietveld-analysis program RIETAN98 and its applications to zeolites", Mater. Sci. Forum, 198 (2000)321-324.

7) I.D.Brown and D.Altermatt: "Bond-valence parameters obtained from a systematic analysis of the Inorganic Crystal Structure Database", Acta Cryst. B, 41(1985)244-247.

8) K.-I.Kobayashi, T.Kimura, Y.Tomioka, H.Sawada, and K.Terakura, and Y.Tokura: "Intergrain tunneling magnetoresistance in polycrystals of the ordered double perovskite $\mathrm{Sr}_{2} \mathrm{FeReO}_{6}$ ", Phys. Rev. B, 59(1999) 11159-11162. 